\title{
The prognosis of giant cell tumor of bone and the vital risk factors that affect its postoperative recurrence: a meta-analysis
}

\author{
Xunge $\operatorname{Lin}^{1 \#}$, Jiaqi Liu ${ }^{2 \#}$, Meng $\mathrm{Xu}^{1 \wedge}$ \\ ${ }^{1}$ Department of Oncology, The First Affiliated Hospital, Jinan University, Guangzhou, China; ${ }^{2}$ Department of Orthopaedics, The First Affiliated \\ Hospital, Jinan University, Guangzhou, China \\ Contributions: (I) Conception and design: M Xu; (II) Administrative support: M Xu; (III) Provision of study materials or patients: X Lin, J Liu; (IV) \\ Collection and assembly of data: All authors; (V) Data analysis and interpretation: All authors; (VI) Manuscript writing: All authors; (VII) Final \\ approval of manuscript: All authors. \\ "These authors contributed equally to this work. \\ Correspondence to: Meng Xu. Department of Oncology, The First Affiliated Hospital, Jinan University, No. 613, Huangpu West Road, Tianhe \\ District, Guangzhou 510627, China. Email: xmjnu20@163.com.
}

Background: The purpose of this study is to analyze the overall prognosis of giant cell tumor of bone (GCTB) and the risk factors that affect its postoperative recurrence.

Methods: The databases of PubMed, Cochrane, Web of Science, Embase, China national knowledge infrastructure, China Biology Medicine disc, and Wanfang were searched until 20 June 2020. Following patients, intervention, comparator, outcomes, study design (PICOS) guidelines, eligible articles were defined as studies evaluating the overall prognosis of GCTB and the risk factors that affect its postoperative recurrence. The association between five risk factors (surgical methods, whether there is soft tissue invasion, tumor size, p53 expression, vascular endothelial growth factor (VEGF) expression) and the recurrence of GCTB were calculated using fixed-effects or random-effects models. The heterogeneity of the odd ration (OR) and effect size (ES) of each study was quantified using Cochran's Q test and Higgins-I2 statistic. The publication bias was analyzed through the drawing of the funnel diagram.

Results: A total of 10 studies were included in the study. We found that the probability of recurrence of patients who choose simple curettage is 5.75 times that of patients who choose amputation or total resection. Patients with soft tissue invasion are 3.76 times more likely to relapse than non-invasive GCTB. The probability of recurrence of patients with tumors larger than $5 \mathrm{~cm}$ is 2.8 times that of patients with tumors smaller than. Patients with positive expression of p53 are 3.82 times more likely to relapse than patients with negative expression. And patients with positive expression of VEGF are 3.82 times more likely to relapse than patients with negative expression.

Conclusions: In conclusion, our analysis of five risk factors can be used to measure the recurrence of GCTB and provide important preoperative recommendations for patients with GCTB.

Keywords: Giant cell tumor of bone (GCTB); osteoclastoma; prognosis; recurrence; risk Factors

Submitted Sep 19, 2020. Accepted for publication Jan 29, 2021.

doi: $10.21037 /$ tcr-20-3100

View this article at: http://dx.doi.org/10.21037/tcr-20-3100

\footnotetext{
$\wedge$ ORCID: 0000-0002-1559-8178.
} 


\section{Introduction}

Giant cell tumor of bone (GCTB) is a rare benign primary bone tumor (1). It has local lytic bone destruction, local invasiveness, potential malignancy, and metastatic tendency (2). GCTB usually occurs in patients with mature bone development, and it is more common in people aged 20-40. It mostly occurs in females and can produce expansive or osteolytic lesions $(3,4)$. The most common disease sites are knee (usually located at the distal end of the femur and the proximal end of the tibia), proximal femur, distal radius, distal tibia, and the area adjacent to the sacroiliac joint of the sacrum, followed by flat bones, the backbone of any long bone and the anterior part of the axial bone $(5,6)$.

Currently, the diagnosis of GCTB is primarily dependent on histological analysis due to the limited value of clinical and radiological details. Local pain and swelling are the most frequent symptoms in patients with GCTB (7). Recent reports revealed that tumor progression and prognosis is determined not only by tumor characteristics but also by the host inflammatory response $(8,9)$. It has increasingly been recognized that tumor-infiltrating inflammatory cells are responsible for producing inflammatory mediators and cytokines that induce angiogenesis, tumor growth, invasion, and metastasis (10). Local recurrence and remote metastases are also found in patients with malignant giant cell tumor of bone (MGCTB). The lung is the most prominent source of metastases, contributing to adverse effects. There is currently no consensus on the treatment of GCTB. Conventional therapies involve surgery alone or surgery paired with radiotherapy and chemotherapy; however, the result is not obvious. There are few prognostic studies of GCTB due to lack of cases and long-term followup evidence. In a review of 26 primary GCTB cases, the total mortality rate was $16 \%$ and the 5 -year survival rate was $87 \%$ (11). However, other studies have reported poor prognosis for patients with GCTB with a limited duration of survival after diagnosis (12).

At present, there are many methods including chemotherapy, radiotherapy, surgery, and joint replacement are employed for the treatment of GCTB (13). For decades, surgery has remained the main treatment strategy for the disease. The goal of surgical treatment is to remove the tumor as much as possible, preserve the function of the affected area, and prevent postoperative tumor recurrence. For resectable GCTB, the main surgical methods include intralesional curettage (IC) and wide excision (WE) methods. Currently, numerous literature reports about the curative effect of certain surgical procedures; however, there are few comparative studies about the effects of various surgical procedures on the recurrence of GCTB. Moreover, there are few related studies on the prognostic factors and prognosis of GCTB recurrence after surgery. Therefore, a more comprehensive meta-analysis is needed to compare the effects of different surgical methods on the recurrence of GCTB and to provide evidence-based medicine for clinical treatment. We present the following article in accordance with the PRISMA reporting checklist (available at http://dx.doi.org/10.21037/tcr-20-3100).

\section{Methods}

\section{Literature research}

As of 20 June 2020, a comprehensive literature search was conducted in the databases of PubMed, Cochrane Library, Web of Science, Embase, China national knowledge infrastructure, China Biology Medicine disc, and Wangfang. Based on the PRISMA (14) guidelines (preferred reporting items for systematic reviews and meta-analysis), this study used evidence-based models to construct PICO problem models. (PICO: Participants, Intervention, Control, and Outcomes). The following terms were used to identify research: Giant cell tumor of bone, osteoclastoma; Prognosis; Recurrence; prognostic factors.

\section{Inclusion and exclusion criteria}

PICOS guidelines were followed by the inclusion and exclusion of the searched studies as shown in Table 1.

\section{Data extraction and quality assessment}

The two authors independently reviewed all eligible studies and extracted data. The following information was collected: first author's name, year of publication, country, ethnicity, outcome measures ES, OR, and 95\% CI. Any disagreement was resolved by discussions. First, the title and abstract were carefully evaluated, and then the randomized controlled trial, prospective study, case-control study potential articles were comprehensively evaluated.

\section{Statistical analysis}

The heterogeneity of the OR and ES of each study 
Table 1 PICOS criteria for inclusion and exclusion of studies

\begin{tabular}{lll}
\hline Parameters & Inclusion criteria & Exclusion criteria \\
\hline Patients & $\begin{array}{l}\text { A patient with GCTB by X-ray, CT, MRI, and fine-needle aspiration } \\
\text { biopsy before the operation }\end{array}$ & Not a disease of the GCTB \\
Types of cases & $\begin{array}{l}\text { Postoperative recurrence cases, postoperative complications } \\
\text { cases, and postoperative site function evaluation }\end{array}$ & - \\
Study design & $\begin{array}{l}\text { Randomized controlled trials, prospective studies, and } \\
\text { case-control studies }\end{array}$ & $\begin{array}{l}\text { Systematic reviews, comments, reviews, and animal } \\
\text { experiment literature }\end{array}$ \\
Comparator & $\begin{array}{l}\text { The study provided sufficient information to calculate the odds } \\
\text { ratio (OR), effect size (ES), and } 95 \% \mathrm{Cl}\end{array}$ & $\begin{array}{l}\text { Studies that do not provide the necessary data; the } \\
\text { quality of study is poor, and duplicate documents }\end{array}$ \\
\hline
\end{tabular}

was quantified using Cochran's Q test and Higgins- $\mathrm{I}^{2}$ statistic. A $\mathrm{P}<0.1$ for the $\mathrm{Q}$-test or $\mathrm{I}^{2}>50 \%$ was considered statistically significant, and the random-effects model was used, otherwise, the fixed-effects model was used. For assessment of reporting bias, if our review had a sufficient number of included trials that were available in the metaanalysis, a funnel plot and statistic test was generated to analyze the potential reporting bias as well as small study effects. Subgroup analysis was performed based on sample size, country, treatment, and the cut-off value. Most of the statistical analyses in this study used STATA software (version 11.2; StataCorp LP, College Station, TX, USA).

\section{Results}

\section{Study characteristics}

The original search included 162 records and after deleting systematic reviews, comments, reviews, and animal experiment literature, 118 records remained. A total of 118 full-text articles were evaluated when selecting titles and abstracts. Of them, $87 \mathrm{did}$ not meet the inclusion criteria and were therefore excluded, while 31 records remained. Through reading the full text, we excluded 19 documents that did not meet the end effect size or could not provide the effect size data. At the same time, 3 documents were excluded whose full text and document data cannot be obtained. As a result, 10 eligible studies, comprising a total of 675 patients, were included in the meta-analysis.

All studies were published between 2004 and 2020. Ten studies (15-24) explored the prognostic role of after surgery for patients. All included studies were divided into five groups according to all prognostic factors that may cause postoperative GCTB recurrence: surgical methods, whether there is soft tissue invasion, tumor size, p53 expression, VEGF expression.

\section{Meta-analysis of the overall prognosis of GCTB}

The 10 documents in this study have passed the heterogeneity test, $\mathrm{I}^{2}=77.31 \%>50 \%$, and the $\mathrm{Q}$ test $\mathrm{P}<0.1$, suggesting that there is significant heterogeneity between the selected documents in this study, and random effects can be selected. Meta-analysis can also continue to conduct sensitivity analysis to investigate the causes of heterogeneity. Sensitivity analysis showed that none of the literature has greatly interfered with the results of this meta-analysis, which means that this study has good stability (Table 2). A meta-analysis based on random effects showed that the overall recurrence rate of GCTB after treatment was $29 \%$, with a high recurrence rate (ES: 0.29, 95\% CI: 0.25-0.32, $\mathrm{Z}: 11.84, \mathrm{P}<0.05)$ (Figure 1). And the funnel chart obtained from the analysis is relatively symmetrical (Figure 2), suggesting that the literature included in the study is less biased.

\section{Meta-analysis of surgical methods for recurrence of GCTB}

It can be seen from Figure 3 that the meta-analysis of the 4 studies on the recurrence of GCTB by surgical methods is obviously heterogeneous, with $\mathrm{I}^{2}>50 \%$. Therefore, the sensitivity analysis continues and it is found that Minghui $\mathrm{Li}$ (in 2018) is the main reason for heterogeneity. After deleting the study, a meta-analysis was performed again (Figure 4), and it was found that the choice of surgical method was a prognostic factor for recurrence of GCTB (OR: 7.80, 95\% CI: 3.82-15.90, Z: 5.65, $\mathrm{P}<0.05$ ), and the heterogeneity has not existed $\left(\mathrm{I}^{2}: 9 \%<50 \%, \mathrm{P}=0.33>0.1\right)$. Further, the funnel chart obtained from the analysis is relatively symmetrical (Figure 5). Taken together, the probability of recurrence of patients who choose simple curettage is 5.75 times that of patients who choose amputation or total resection. 
Table 2 Studies included in this review

\begin{tabular}{|c|c|c|c|c|c|c|}
\hline Studies & Study type & $\begin{array}{l}\text { Sample } \\
\text { size }\end{array}$ & $\begin{array}{c}\text { Gender } \\
\text { (male/female) }\end{array}$ & Age, years & Follow-up time & Prognosis \\
\hline Chen et al. (in 2004) & Retrospective study & 42 & - & - & At least 2 years & $19 / 42$ \\
\hline Wang et al. (in 2005) & Retrospective study & 65 & $34 / 31$ & 30.1 (10 to 65$)$ & Not specified & $19 / 65$ \\
\hline Zhang et al. (in 2005) & Retrospective study & 82 & $46 / 36$ & 31.03 & $\begin{array}{c}\text { 10-96 months, } 36.4 \text { months } \\
\text { averagely }\end{array}$ & $29 / 82$ \\
\hline $\begin{array}{l}\text { van der Heijden et al. } \\
\text { (in 2014) }\end{array}$ & Retrospective study & 26 & $11 / 15$ & $\begin{array}{c}\text { A median of } 41 \\
\text { (14 to } 66 \text { years old) }\end{array}$ & $\begin{array}{l}\text { Median follow-up time } 98 \\
\text { months (6-229 months) }\end{array}$ & $15 / 26$ \\
\hline $\begin{array}{l}\text { Yalcinkaya et al. } \\
\text { (in 2015) }\end{array}$ & Retrospective study & 42 & $20 / 22$ & - & Not specified & $10 / 42$ \\
\hline He et al. (in 2019) & Retrospective study & 55 & - & - & - & $23 / 55$ \\
\hline
\end{tabular}

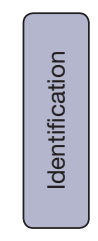

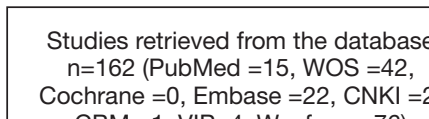

Cochrane $=0$, Embase $=22, \mathrm{CNKI}=2$ $\mathrm{CBM}=1$, VIP=4, Wanfang $=76$ )
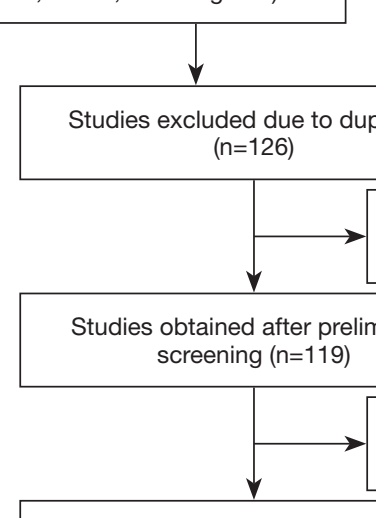
Documents obtained through other resources $(n=0)$

ded due to duplicate $\mathrm{n}=126)$

Median follow-up time 98

$5 / 26$

Not specified

$0 / 42$

$8 / 73$

95.3 (21 to 321$)$

$23 / 55$
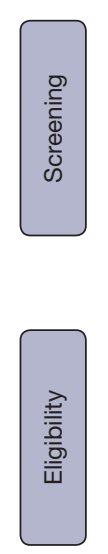

Studies included after browsing the abstract $(n=32)$

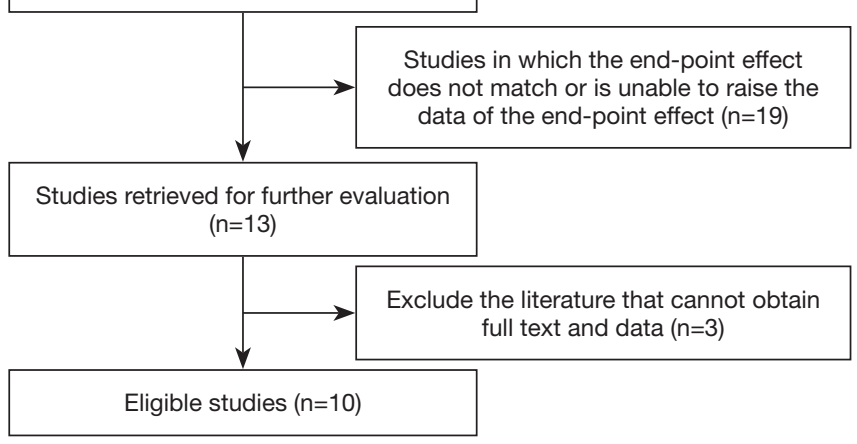

Figure 1 Flow diagram of study selection. 


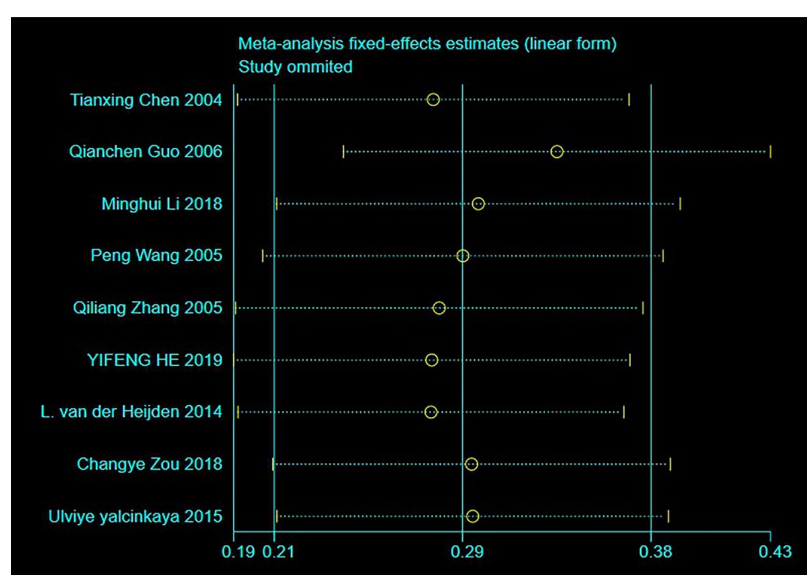

Figure 2 Sensitivity analysis of this study.

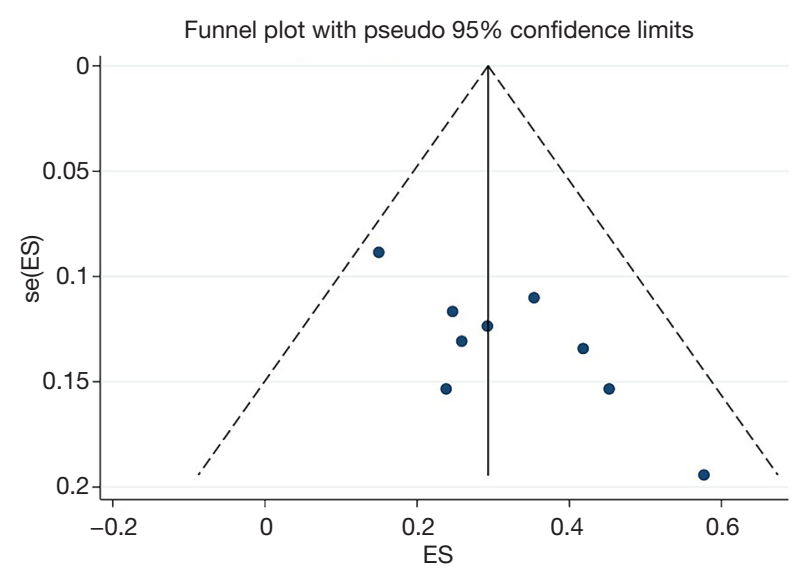

Figure 4 Funnel diagram of this study.

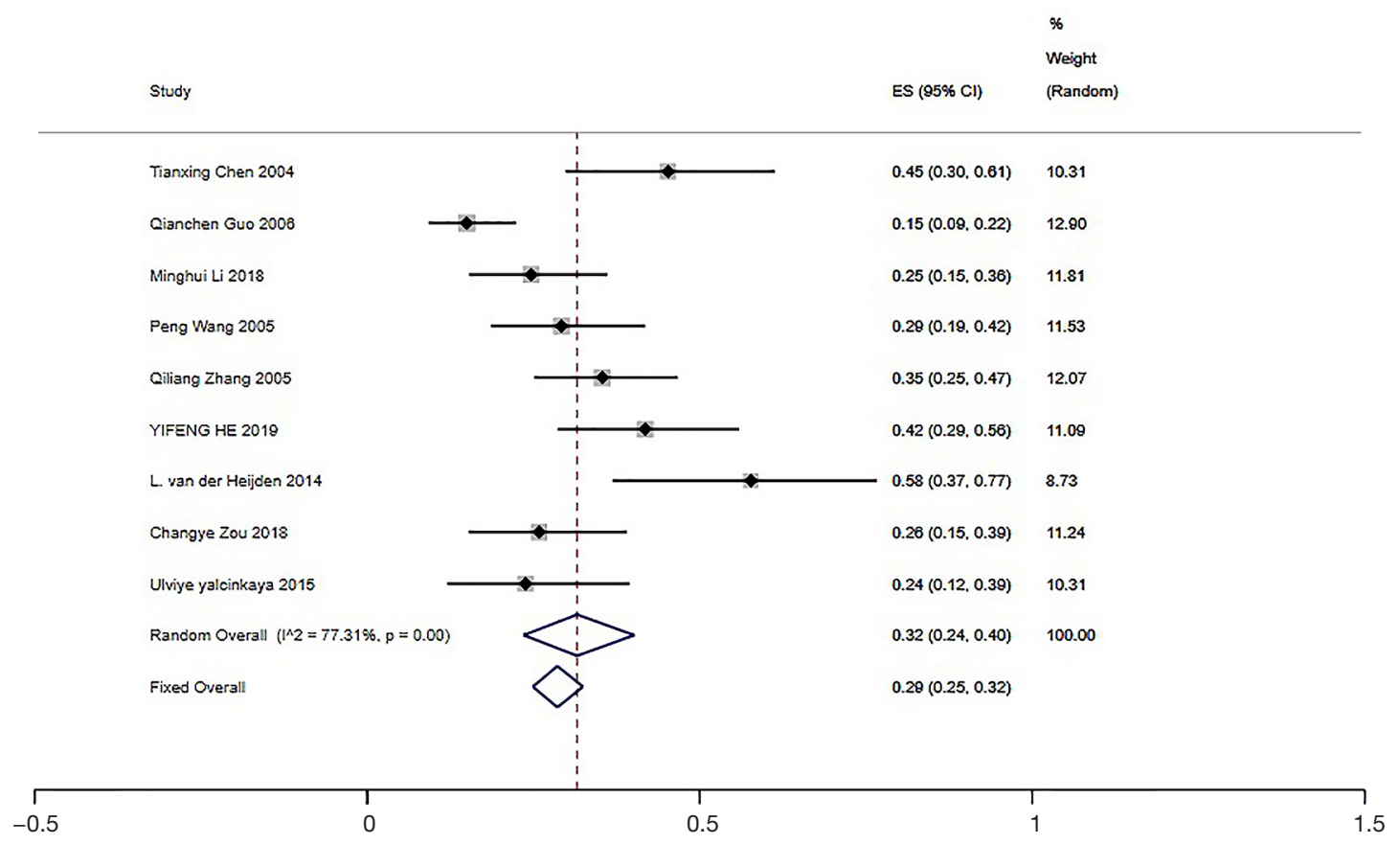

Figure 3 Forest map of a meta-analysis of Random effects.

\section{Meta-analysis of soft tissue invasion for recurrence of GCTB}

It can be clearly seen from Figure 6 that $\mathrm{I}^{2}=0 \%<50 \%$, $\mathrm{P}=0.78>0.1$, there is no heterogeneity in this study, so the fixed effect was selected for meta-analysis of surgical factors. It was found that whether there is soft tissue invasion, GCTB recurrence is one of the prognostic factors (OR: 3.7, 95\% CI: 1.61-8.78, Z: 3.06, $\mathrm{P}<0.05)$. The funnel chart obtained from the analysis is relatively symmetrical (Figure 7), suggesting that the literature included in the study is not biased. Taken together, patients with soft tissue invasion are 3.76 times more likely to relapse than non-invasive GCTB.

\section{Meta-analysis of tumor size for recurrence of GCTB}

It can be clearly seen from Figure 8 that $\mathrm{I}^{2}=0 \%<50 \%$, $\mathrm{P}=0.7>0.1$, and there is no heterogeneity in this study. 


\begin{tabular}{|c|c|c|c|c|c|c|c|c|}
\hline Stucty or Subgroup & log[Odds Ratio] & SE & Weight & $\begin{array}{l}\text { Odds Ratio } \\
\text { IV. Fixed. } 95 \% \mathrm{Cl}\end{array}$ & & $\begin{array}{r}\text { Odds } \\
\text { N. Fixed }\end{array}$ & $\begin{array}{l}\text { Ratio } \\
.95 \% \mathrm{Cl}\end{array}$ & \\
\hline Minghui Li2018 & -1.96611286 & 0.89548492 & $14.2 \%$ & $0.14[0.02,0.81]$ & & & & \\
\hline Peng Wang2005 & 3.57713751 & 1.17378201 & $8.2 \%$ & $35.77[3.58,356.99]$ & & & & \\
\hline Qianchen Guo2006 & 2.23921922 & 0.70761919 & $22.7 \%$ & $9.39[2.35,37.57]$ & & & & \\
\hline Tianxing Chen2004 & 1.74919986 & 0.45440114 & $55.0 \%$ & $5.75[2.36,14.01]$ & & & & \\
\hline Total $(95 \% \mathrm{Cl})$ & & & $100.0 \%$ & $4.42[2.28,8.54]$ & & & & \\
\hline \multicolumn{5}{|c|}{$\begin{array}{l}\text { Heterogeneity: } \text { Chi } i^{2}=19.50, d f=3(P=0.0002) ; I^{2}=85 \% \\
\text { Test for overall effect: } Z=4.41(P<0.0001)\end{array}$} & & $\begin{array}{l}0.1 \\
\text { s [experimental] }\end{array}$ & Favou & $100^{\circ}$ \\
\hline
\end{tabular}

Figure 5 A meta-analysis of recurrence of GCTB with surgical methods: part 1.

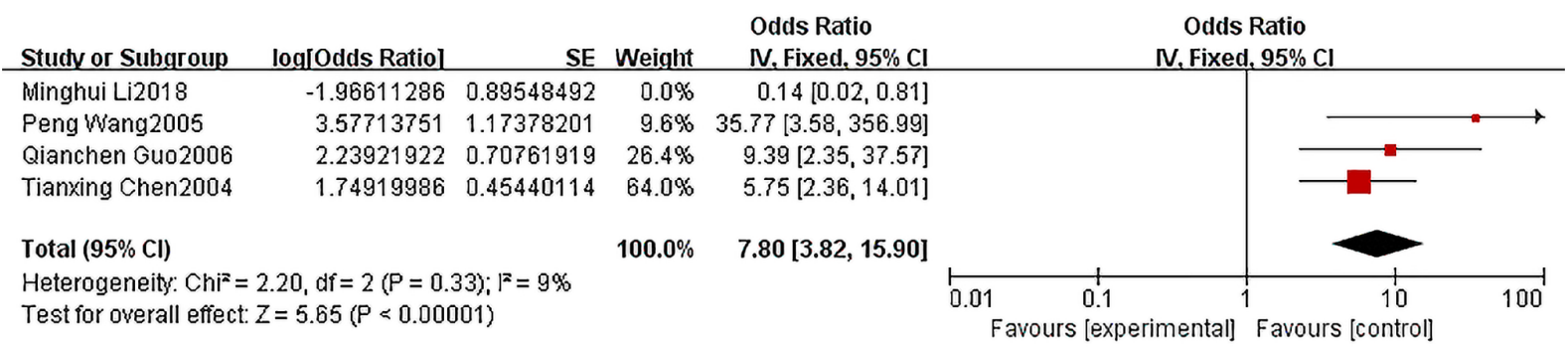

Figure 6 Meta-analysis of recurrence of GCTB with surgical methods: part 2.

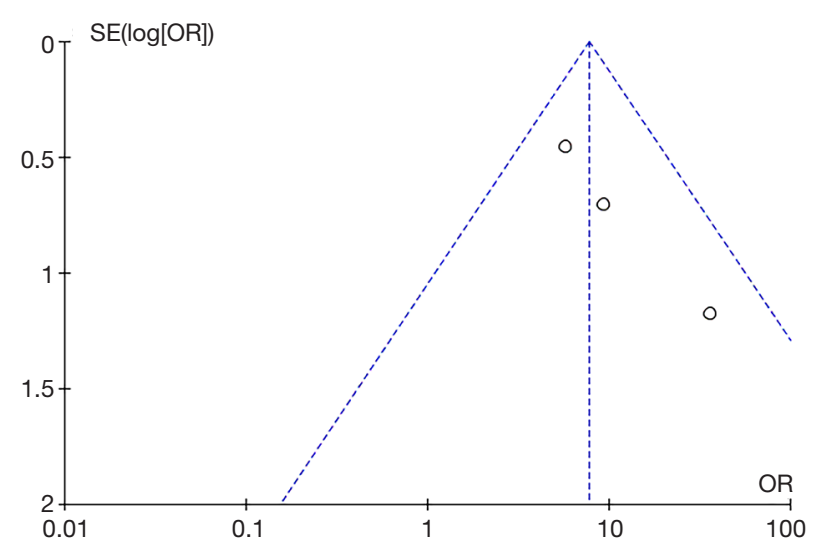

Figure 7 Funnel diagram of this study.

Therefore, the fixed effect was selected for the meta-analysis of surgical factors. The tumor size was found as one of the prognostic factors for tumor recurrence (OR: 2.80, 95\% CI: $1.42-5.52, \mathrm{Z}: 2.97, \mathrm{P}<0.05)$. The funnel chart obtained from the analysis is relatively symmetrical (Figure 9), suggesting that the literature included in the study is not biased. In short, the probability of recurrence of patients with tumors larger than $5 \mathrm{~cm}$ is 2.8 times that of patients with tumors smaller than.

\section{Meta-analysis of $p 53$ for the recurrence of GCTB}

It can be clearly seen from Figure 10 that $\mathrm{I}^{2}=0 \%<50 \%$, $\mathrm{P}=0.46>0.1$, and there is no heterogeneity in this study. Therefore, the fixed effect was selected for meta-analysis of surgical factors, and finally it is concluded that the expression of $\mathrm{p} 53$ is one of the prognostic factors for cell tumor recurrence (OR: 3.82, 95\% CI: 1.64-8.88, Z: 3.11, $\mathrm{P}<0.05)$. The funnel chart obtained from the analysis is relatively symmetrical (Figure 11), suggesting that the literature included in the study is not biased. In short, patients with positive expression of p53 are 3.82 times more likely to relapse than patients with negative expression.

\section{Meta-analysis of VEGF for the recurrence of GCTB}

It can be clearly seen from Figure 12 that $\mathrm{I}^{2}=0 \%<50 \%$, $\mathrm{P}=0.97>0.1$, and there is no heterogeneity in this study. Therefore, the fixed effect was selected for meta-analysis of surgical factors, and finally it is concluded that the expression of VEGF is one of the prognostic factors for cell tumor recurrence (OR: 3.56, 95\% CI: 1.60-7.92, Z: 3.12, $\mathrm{P}<0.05)$ (Figure 13). The funnel chart obtained from the analysis is relatively symmetrical (Figures 14,15), suggesting that the literature included in the study is not biased. In 


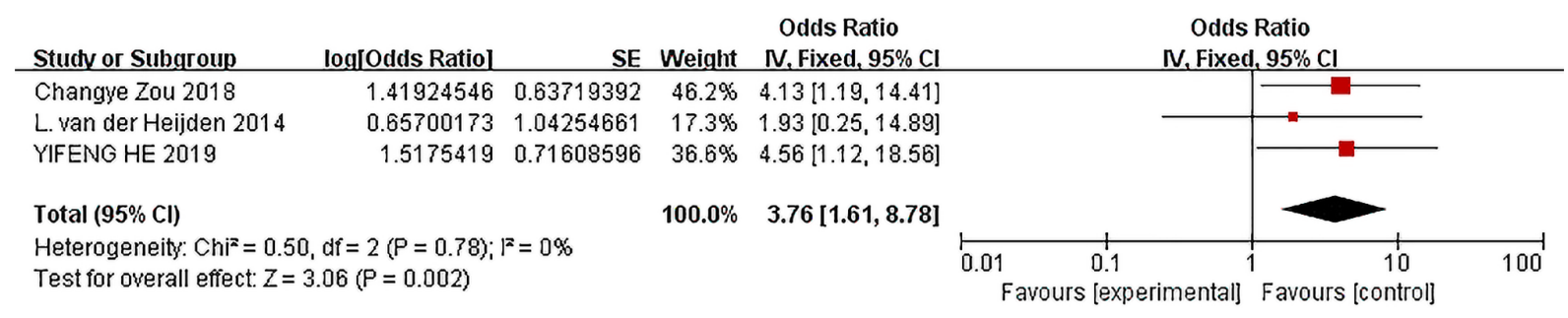

Figure 8 Meta-analysis of soft tissue invasion in the recurrence of GCTB.

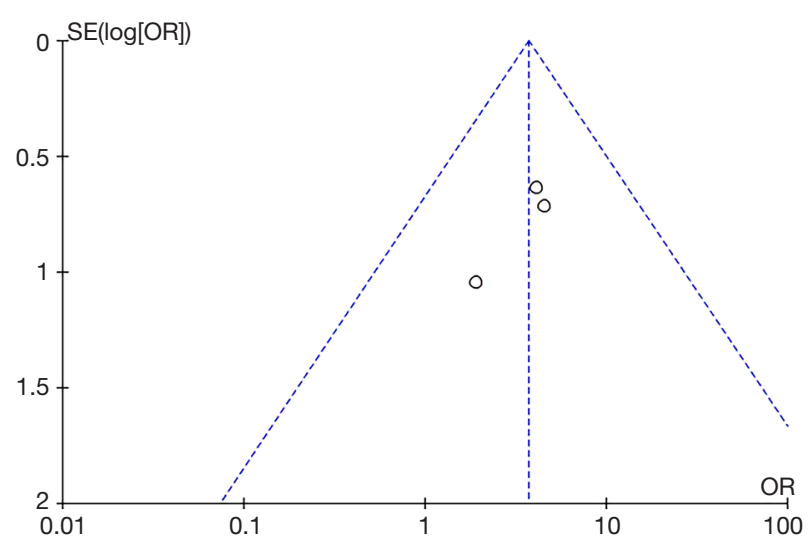

Figure 9 Funnel diagram of this study.

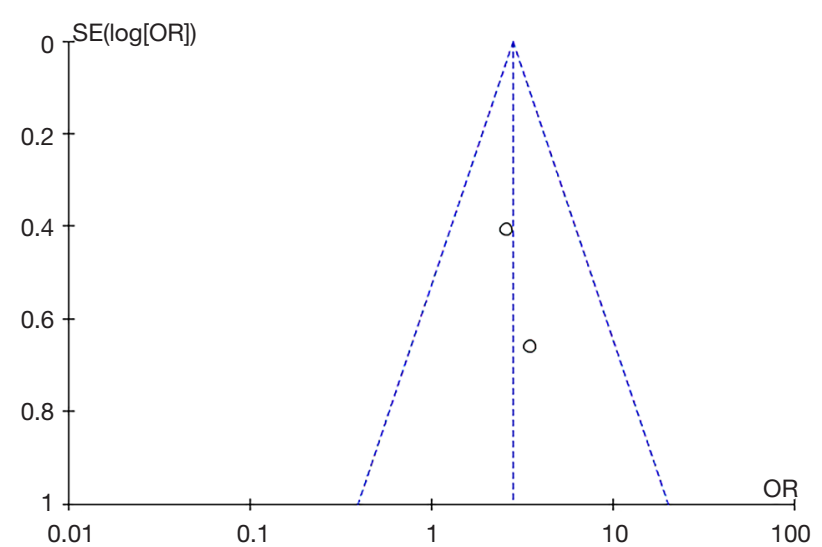

Figure 11 Funnel diagram of this study.

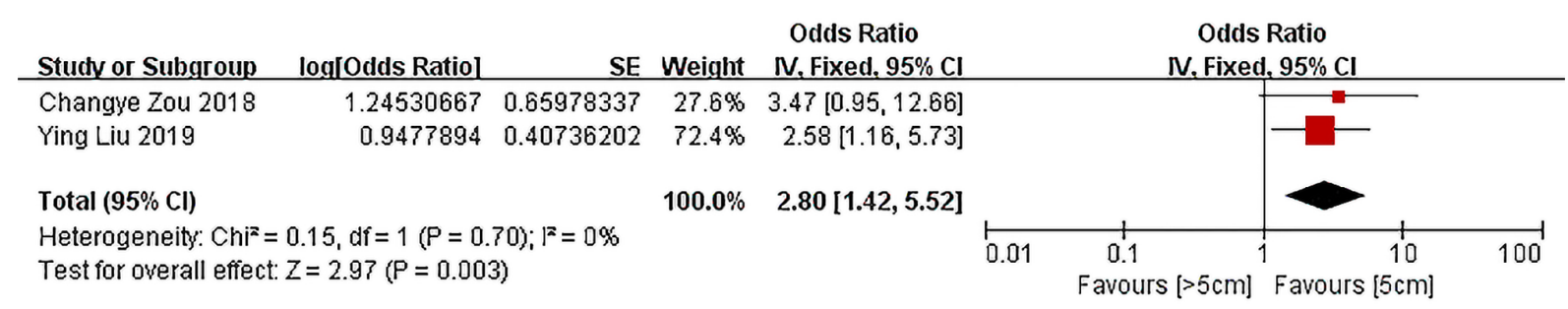

Figure 10 Meta-analysis of tumor size on the recurrence of GCTB.

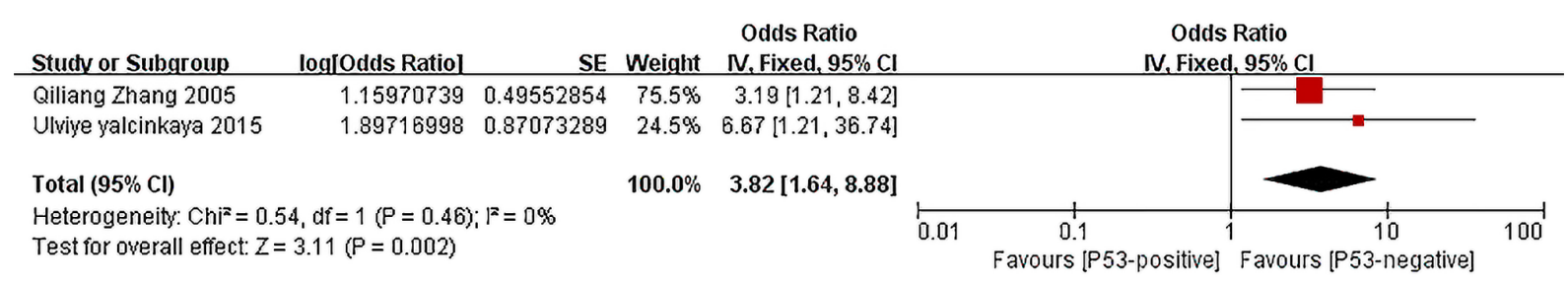

Figure 12 Meta-analysis of p53 in the recurrence of GCTB. 


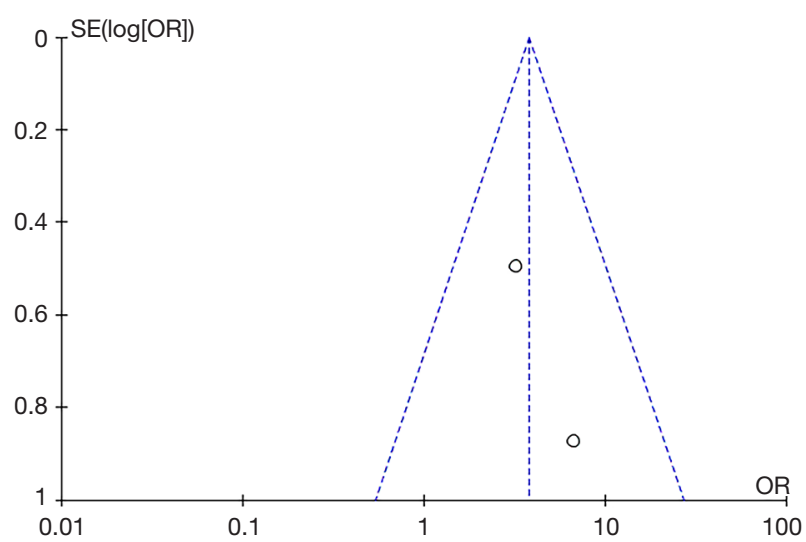

Figure 13 Funnel diagram of this study.

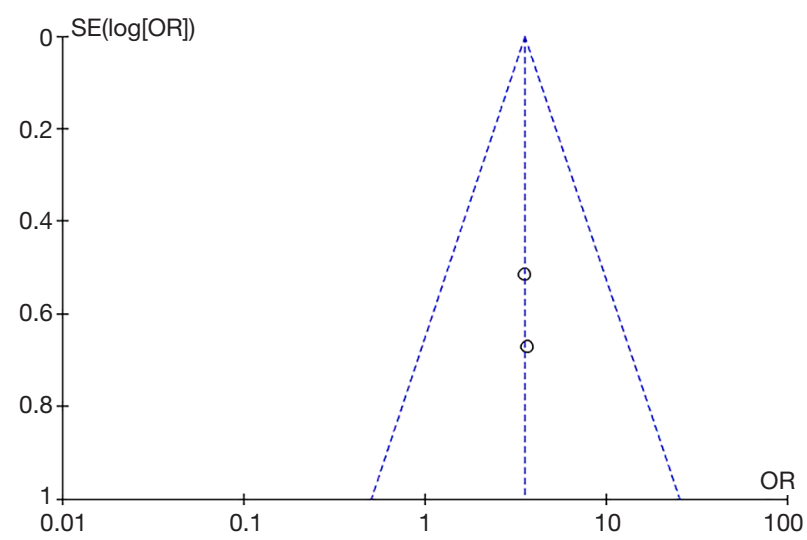

Figure 15 Funnel diagram of this study.

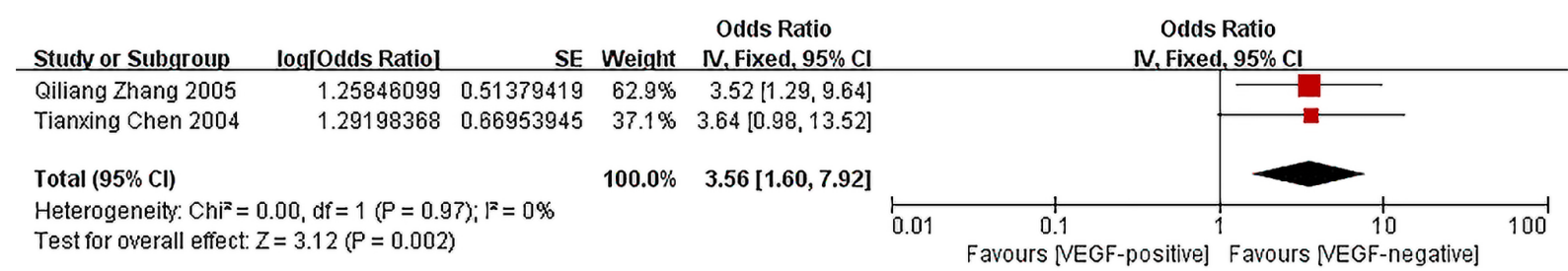

Figure 14 Meta-analysis of recurrence of GCTB by VEGF.

short, patients with positive expression of VEGF are 3.82 times more likely to relapse than patients with negative expression.

\section{Discussion}

\section{Principal finding and clinical interpretation}

GCTB is a potentially malignant tumor that grows actively and easily recurs. At the same time, it is well known that GCTB is one type of giant cell-rich lesion of bone (3), but its specific cellular components are complex and biological characteristics are variable. The local recurrence rate of GCTB has been reported as $5 \%$ to $50 \%$ (25). Few studies have evaluated the overall prognosis of GCTB after treatment, but our study confirmed that the overall recurrence rate after GCTB treatment was $29 \%(\mathrm{ES}=0.29$, 95\% CI: $0.25-0.32$, Z: $11.84, \mathrm{P}<0.05)$, the recurrence rate is higher.

GCTB is a potentially malignant tumor that grows actively and easily recurs. It is well known that GCTB is a bone lesion rich in giant cells (3), but its specific cellular components are complex and biological characteristics are variable. The local recurrence rate of GCTB has been reported as $5 \%$ to $50 \%$ (3). Few studies have evaluated the overall prognosis of GCTB after treatment, but our study confirmed that the overall recurrence rate after GCTB treatment was $29 \%$ (ES: 0.29, 95\% CI: 0.25-0.32, Z: 11.84 , $\mathrm{P}<0.05)$, the recurrence rate is higher. Our research found that such a high tumor recurrence rate may be related to the following reasons: surgical methods (OR: 7.80, 95\% CI: 3.82-15.90, Z: $5.65, \mathrm{P}<0.05)$, whether there is soft tissue invasion (OR: 3.7, 95\% CI: 1.61-8.78, Z: 3.06, $\mathrm{P}<0.05$ ), tumor size (OR: 2.80, 95\% CI: 1.42-5.52, Z: 2.97, $\mathrm{P}<0.05$ ), p53 expression(OR: 3.82, 95\% CI: 1.64-8.88, Z: 3.11, $\mathrm{P}<0.05$ ), VEGF expression (OR: 3.56, 95\% CI: 1.60-7.92, $\mathrm{Z}: 3.12, \mathrm{P}<0.05)$.

Our research found that the probability of recurrence of patients who choose simple curettage is 5.75 times that of patients who choose amputation or total resection. At present, the general principle of clinical treatment of GCTB is to use surgical treatment as the mainstream, and the purpose of treatment is to completely remove the local tumor, to maximize the preservation of adjacent joint function, and try to avoid postoperative tumor recurrence and complications (26-28). But the specific methods have not reached a consensus. Simple curettage has a simple 
operation, less damage, and better postoperative function, but the recurrence rate is higher than amputation or total resection. Although amputation or total resection has a low recurrence rate, the postoperative functional recovery of patients is poor. To protect the function of the affected area to the greatest extent, improve the prognosis of the patient, and reduce the recurrence rate. Some scholars have tried to combine various chemical (phenol, absolute alcohol, hydrogen peroxide, etc.) or physical (high-speed drill, electric knife cauterization, microwave ablation, liquid nitrogen freezing, etc.) adjuvant therapies after intralesional resection surgery. However, there is no large amount of data to confirm that the postoperative recurrence rate of combined adjuvant therapy is lower than amputation or total resection.

We analyzed the correlation between preoperative imaging examination and tumor immunohistochemical technique and GCTB recurrence. First, the preoperative imaging characteristics and the recurrence of GCTB were analyzed. We found that patients with soft tissue invasion and tumors larger than $5 \mathrm{~cm}$ are more likely to relapse GCTB. This suggests that such patients need to be followed up and regularly reviewed after surgery. In addition, p53 is a famous tumor suppressor gene, and there is evidence in the literature that $\mathrm{p} 53$ may be implicated in GCTB behavior (28). In this study, we found that patients with positive expression of p53 are 3.82 times more likely to relapse than patients with negative expression. This result also supports the suggestion that many scholars put p53 as a marker of GCTB biological behavior (29). Studies have found that VEGF is overexpressed in GCTB tissue and its adjacent non-cancerous tissue samples, and may play an important role in the occurrence, invasion, metastasis, and recurrence of GCTB $(22,30)$. Our analysis found that patients with positive expression of VEGF are 3.82 times more likely to relapse than patients with negative expression. This suggests that the expression status of VEGF helps to evaluate the prognosis of GCTB patients.

\section{Limitations}

However, our research has some limitations. First, there is too much heterogeneity between studies. Subgroup analysis found no potential sources of heterogeneity. Second, the severity of the patient population of all the included studies and the differences between different individuals limit our conclusions. Third, the small number of people involved may also limit our conclusions.
We did not specify how sources of heterogeneity were explored. Because of the risk factors of recurrence in the study, OR was used as the effect quantity. Only two included articles had HR, so it was not significant to include them. Some literature did not explicitly mention OR, so SPSS statistical software was used to calculate OR.

\section{Conclusions}

In conclusion, this study can provide significant guidance for the prognosis and reexamination after GCTB. Our result showed that the five risk factors may assess the recurrence of GCTB and provide crucial preoperative recommendations to the surgeon and health care team for patients with GCTB. The findings of this study suggest that while choosing an appropriate surgical procedure, we should fully consider the impact of different risk factors on the recurrence rate.

\section{Acknowledgments}

Special thanks are given to Dr. Ryan from Wenxing Language Editing Service.

Funding: None.

\section{Footnote}

Reporting Checklist: The authors have completed the PRISMA reporting checklist. Available at http://dx.doi. org/10.21037/tcr-20-3100

Conflicts of Interest: All authors have completed the ICMJE uniform disclosure form (available at http://dx.doi. org/10.21037/tcr-20-3100). The authors have no conflicts of interest to declare.

Ethical Statement: The authors are accountable for all aspects of the work in ensuring that questions related to the accuracy or integrity of any part of the work are appropriately investigated and resolved.

Open Access Statement: This is an Open Access article distributed in accordance with the Creative Commons Attribution-NonCommercial-NoDerivs 4.0 International License (CC BY-NC-ND 4.0), which permits the noncommercial replication and distribution of the article with the strict proviso that no changes or edits are made and the original work is properly cited (including links to both the 
formal publication through the relevant DOI and the license). See: https://creativecommons.org/licenses/by-nc-nd/4.0/.

\section{References}

1. Lipplaa A, Dijkstra S, Gelderblom H. Challenges of denosumab in giant cell tumor of bone, and other giant cell-rich tumors of bone. Curr Opin Oncol 2019;31:329-35.

2. War AR, Dang K, Jiang S, et al. Role of cancer stem cells in the development of giant cell tumor of bone. Cancer Cell Int 2020;20:135.

3. Raskin KA, Schwab JH, Mankin HJ, et al. Giant cell tumor of bone. J Am Acad Orthop Surg 2013;21:118-26.

4. Zhang J, Li Y, Li D, et al. Clinical effects of three surgical approaches for a giant cell tumor of the distal radius and ulna. Mol Clin Oncol 2016;5:613-7.

5. Larsson SE, Lorentzon R, Boquist L. Giant-cell tumor of bone. A demographic, clinical, and histopathological study of all cases recorded in the Swedish Cancer Registry for the years 1958 through 1968. J Bone Joint Surg Am 1975;57:167-73.

6. Prince HL. Giant cell tumor of the os calcis. JBJS 1916;2:641-53.

7. Nascimento AG, Huvos AG, Marcove RC. Primary malignant giant cell tumor of bone. A study of eight cases and review of the literature. Cancer 1979;44:1393-402.

8. Balkwill F, Mantovani A. Inflammation and cancer: back to Virchow? Lancet 2001;357:539-45.

9. He W, Wei M, Yang X, et al. Do inflammatory markers predict prognosis in patients with synchronous colorectal cancer? Medicine 2017;96:e6607.

10. Meaney CL, Zingone A, Brown D, et al. Identification of serum inflammatory markers as classifiers of lung cancer mortality for stage I adenocarcinoma. Oncotarget 2017;8:40946.

11. Domovitov SV, Healey JH. Primary malignant giant-cell tumor of bone has high survival rate. Ann Surg Oncol 2010;17:694-701.

12. Mondal A, Kundu B, Gupta S, et al. Secondary malignant giant cell tumour of bone--a study of five cases with short review of literature. Indian J Pathol Microbiol 2002;45:273.

13. Montgomery C, Couch C, Emory CL, et al. Giant cell tumor of bone: review of current literature, evaluation, and treatment options. J Knee Surg 2019;32:331-6.

14. Tierney JF, Stewart LA, Ghersi D, et al. Practical methods for incorporating summary time-to-event data into meta- analysis. Trials 2007;8:16.

15. Chen T, Yang H, Chen J, et al. Expression of VEGF in giant cell tumor of bone and it's relationship with MVD. Chin J Mod Med 2004;14:48-9.

16. Guo QC, Shen JN, Wang J, et al. Analysis of the factors affecting the recurrence of giant cell tumor of bone. Chin J Surg 2006;44:797-800.

17. He Y, Zhou Y, Zhang J, et al. Tumor immunohistochemistry and preoperative magnetic resonance imaging features predict local recurrence of giant cell tumor of bone following intralesional curettage. Oncol Lett 2019;17:1425-34.

18. Santoni M, Battelli N, Buti S. Durvalumab in Stage III Non-Small-Cell Lung Cancer. N Engl J Med 2018;378:869.

19. Liu Y, Li S, Xu S, et al. Postoperative quality of life and prognosis of 86 patients with primary giant cell tumor of bone. Oncol Prog 2019;17:2172-5.

20. van der Heijden L, van de Sande MAJ, van der Geest ICM, et al. Giant cell tumors of the sacrum - a nationwide study on midterm results in 26 patients after intralesional excision. Eur Spine J 2014;23:1949-62.

21. Wang P, Chen D. An Analysis of Factors Affecting the Prognosis of Giant Cell Tumor of Bone. J New Med 2005;15:38-9.

22. Yalcinkaya U, Ugras N, Kabul S, et al. Prognostic value of p53 protein expression in giant cell tumor of bone. Pol J Pathol 2015;66:389-96.

23. Zhang Q, Yang S, Liu H, et al. Expressions of p53, vascular endothelial growth factor in giant cell tumors of bone and their significance. Chin J Cancer Prev Treat 2005;12:607-10.

24. Zou C, Lin T, Wang B, et al. Managements of giant cell tumor within the distal radius: A retrospective study of 58 cases from a single center. J Bone Oncol 2018;14:100211.

25. Huvos AG. Bone tumors: diagnosis, treatment and prognosis. Philadelphia: W.B. Saunders Co., 1991.

26. Karpik M. Giant Cell Tumor (tumor gigantocellularis, osteoclastoma) - epidemiology, diagnosis, treatment. Ortop Traumatol Rehabil 2010;12:207-15.

27. Puri A, Agarwal M. Treatment of giant cell tumor of bone: Current concepts. Indian J Orthop 2007;41:101-8.

28. Sah PL, Sharma R, Kandpal H, et al. In vivo proton spectroscopy of giant cell tumor of the bone. AJR Am J Roentgenol 2008;190:W133-9.

29. Papanastassiou I, Ioannou M, Papagelopoulos PJ, et 
al. P53 expression as a prognostic marker in giant cell tumor of bone: a pilot study. Orthopedics 2010. doi: 10.3928/01477447-20100329-15.

Cite this article as: Lin $\mathrm{X}, \mathrm{Liu} \mathrm{J}, \mathrm{Xu} \mathrm{M}$. The prognosis of giant cell tumor of bone and the vital risk factors that affect its postoperative recurrence: a meta-analysis. Transl Cancer Res 2021;10(4):1712-1722. doi: 10.21037/tcr-20-3100
30. Zhang J, Dong J, Yang Z, et al. Expression of ezrin, CD44, and VEGF in giant cell tumor of bone and its significance. World J Surg Oncol 2015;13:168. 